\title{
Review: prophylactic use of vitamin D reduces falls in older people
}

Bischoff-Ferrari HA, Dawson-Hughes B, Willett WC, et al. Effect of vitamin D on falls: a meta-analysis. JAMA 2004;291:1999-2006. $Q$ Is prophylactic use of vitamin D effective for preventing falls in older people?

\section{METHODS}

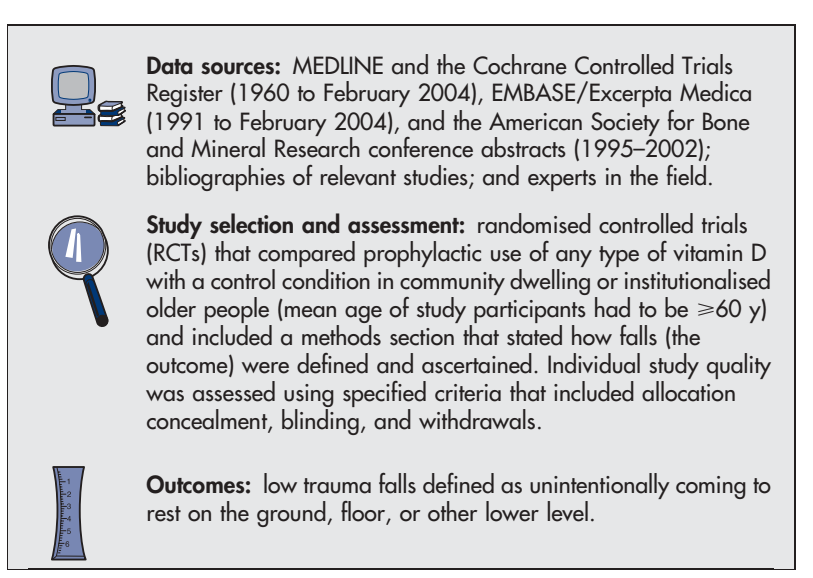

\section{MAIN RESULTS}

5 RCTs $(\mathrm{n}=1237$ ) (mean age $70 \mathrm{y}, 81 \%$ women) met the selection criteria. Comparisons included cholecalciferol $(800 \mathrm{IU} / \mathrm{d})$ plus calcium $(1200 \mathrm{mg} / \mathrm{d})$ with calcium $(1200 \mathrm{mg} / \mathrm{d})(2 \mathrm{RCTs})$; cholecalciferol $(400 \mathrm{IU} / \mathrm{d})$ plus calcium $(800-1000 \mathrm{mg} / \mathrm{d})$ from dairy products with placebo (1 RCT); calcitriol ( $0.5 \mu \mathrm{g} / \mathrm{d}$ ) with placebo ( $\mathrm{RCT}$ ); and $1 \alpha$-calcidiol ( $1 \mu \mathrm{g} / \mathrm{d}$ ) with placebo ( 1 RCT). Meta-analyses using fixed and random effects models showed that fewer participants in the vitamin D group than in the control group had $\geqslant 1$ fall (table). Furthermore, a sensitivity meta-analysis of the 10 "potentially appropriate for inclusion RCTs" $(\mathrm{n}=10001)$ showed that fewer participants in the vitamin $\mathrm{D}$ group than in the control group had $\geqslant 1$ fall (relative risk reduction 13\%, 95\% CI 4 to 20 ).

For correspondence: Dr $\mathrm{H}$ A Bischoff-Ferrari, Division of Aging, Brigham and Women's Hospital, Boston, MA, USA. hbischoł@hsph.harvard.edu

Sources of funding: Harvard/Harford Foundation; Charles A King Trust Fellowship Award; Irene and Fredrick Stare Nutrition Education Fund; Swiss Foundation for Nutrition Research; International Foundation for the Promotion of Nutrition Research and Nutrition Education.

\section{CONCLUSION}

Prophylactic use of vitamin D is effective for reducing falls in older people.

A modified version of this abstract appears in ACP Journal Club.

\section{Commentary}

$\mathrm{R}$ esearch on the beneficial effects of vitamin $D$ for reducing falls is based on the hypothesis that human muscle tissue has specific vitamin $D$ receptors that interact with sufficient concentrations of the vitamin to improve muscle strength. The meta-analysis by Bischoff-Ferrari et al concluded that in older people, prophylactic use of vitamin $D$ is effective for reducing the rate of falls.

Strengths of the review include an extensive literature search, rigorous examination of several high quality studies, and a thorough sensitivity analysis. Inclusion of data from the larger number of participants included in "weaker" studies in the meta-analysis did not change the conclusion but led to a lower estimate of treatment effect, which remained clinically important.

The review does not answer several questions including the optimum dose, route and frequency of administration, and whether it should be given concurrently with calcium to maximise its effect. Bischoff-Ferrari et al suggest that a dose of $700-800 \mathrm{IU} / \mathrm{d}$ may be required and that concurrent calcium may be important. However, no firm conclusions can be made from the available evidence.

The use of vitamin $D$ for fall reduction needs to be considered in addition to many other fall prevention techniques. ${ }^{1}$ People at high risk of falling are often elderly and have multiple pathologies and risks (not fully considered in the studies selected for the meta-analysis). This observation, however, does not discount the need to consider the potential deficiency of vitamin $D$ when assessing older people. The assessment should include establishing the patient's dietary intake of vitamin D, calcium, and other nutrients, especially among those who are housebound and have little exposure to sunlight. If intake is found to be inadequate through history taking and screening, and risk of falling is high, supplementation could be considered as part of an overall strategy to reduce the risk of falls and potential injury. ${ }^{2}$

Heather Monaghan, RN, MHSc Independent Nursing Consultant and Staff Nurse Harrogate, North Yorkshire, UK

1 Gillespie LD, Gillespie WJ, Robertson MC, et al. Interventions for preventing falls in elderly people. Cochrane Database Syst Rev 2003;(4):CD000340.

2 Flicker L, Mead K, Maclnnis RJ, et al. Serum vitamin D and falls in older women in residential care in Australia. J Am Geriatr Soc 2003;51:1533-8.

Vitamin D prophylaxis $v$ a control condition (eg, calcium or placebo) in older people*

\begin{tabular}{|c|c|c|c|c|c|}
\hline \multirow[b]{2}{*}{ Outcome (3 mo to $3 \mathrm{y}$ ) } & \multirow[b]{2}{*}{ Number of RCTs (n) } & \multicolumn{2}{|c|}{ Weighted event rates } & \multirow[b]{2}{*}{$\operatorname{RRR}(95 \% \mathrm{Cl})$} & \multirow[b]{2}{*}{ NNT (CI) } \\
\hline & & Vitamin D & Control & & \\
\hline Participants who had $\geqslant 1$ fall & 5 (1237) & $30 \%$ & $37 \%$ & $19 \%(6$ to 31$)$ & 15 (9 to 52$)$ \\
\hline
\end{tabular}

${ }^{*} \mathrm{RCTs}=$ randomised controlled trials. Other abbreviations defined in glossary; weighted event rates, RRR, NNT, and Cl calculated from data in article using a random-effects model. 